\title{
A phase 2 trial of neoadjuvant metformin in combination with trastuzumab and chemotherapy in women with early HER2- positive breast cancer: the METTEN study
}

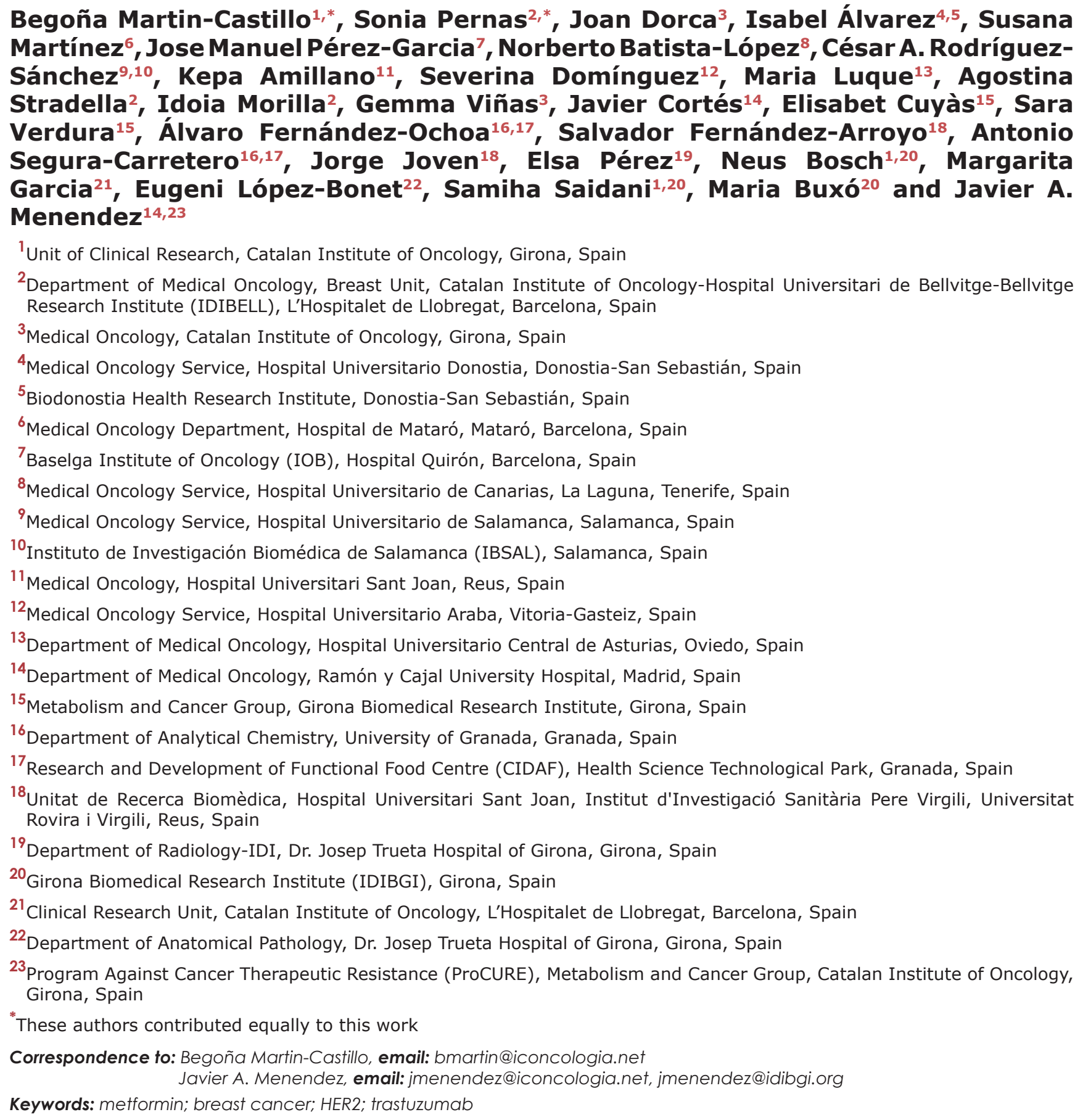

Received: August 29, $2018 \quad$ Accepted: October 21, $2018 \quad$ Published: November 02, 2018

Copyright: Martin-Castillo et al. This is an open-access article distributed under the terms of the Creative Commons Attribution License 3.0 (CC BY 3.0), which permits unrestricted use, distribution, and reproduction in any medium, provided the original author and source are credited. 


\section{ABSTRACT}

The METTEN study assessed the efficacy, tolerability, and safety of adding metformin to neoadjuvant chemotherapy plus trastuzumab in early HER2-positive breast cancer (BC). Women with primary, non-metastatic HER2-positive BC were randomized (1:1) to receive metformin ( $850 \mathrm{mg}$ twice-daily) for 24 weeks concurrently with 12 cycles of weekly paclitaxel plus trastuzumab, followed by four cycles of 3-weekly FE75C plus trastuzumab ( $\operatorname{arm~A),~or~equivalent~regimen~without~metformin~}$ (arm B), followed by surgery. Primary endpoint was the rate of pathological complete response ( $P C R$ ) in the per-protocol efficacy population. PCR rate was numerically higher in the metformin-containing arm A (19 of 29 patients [65.5\%, 95\% CI: 47.3-80.1]) than in arm B (17 of 29 patients [58.6\%, 95\% CI: 40.7-74.5]; OR 1.34 [95\% CI: $0.46-3.89], P=0.589)$. The rate of breast-conserving surgery was $79.3 \%$ and $58.6 \%$ in arm $A$ and $B(P=0.089)$, respectively. Blood metformin concentrations (6.2 $\mathrm{\mu mol} / \mathrm{L}, 95 \% \mathrm{CI}: 3.6-8.8)$ were within the therapeutic range. Seventy-six percent of patients completed the metformin-containing regimen; $13 \%$ of patients in arm A dropped out because of metformin-related gastrointestinal symptoms. The most common adverse events (AEs) of grade $\geq 3$ were neutropenia in both arms and diarrhea in arm A. None of the serious AEs was deemed to be metformin-related. Addition of anti-diabetic doses of metformin to a complex neoadjuvant regimen was well tolerated and safe. Because the study was underpowered relative to its primary endpoint, the efficacy data should be interpreted with caution.

\section{INTRODUCTION}

Metformin, a biguanide derivative that reduces insulin levels, has long been a cornerstone in the treatment of type 2 diabetes (T2D). There is now compelling evidence to incorporate metformin into the armamentarium against cancer, particularly breast cancer (BC). Notwithstanding the limitations of observational studies, many have consistently indicated that metformin can reduce the incidence, outcome, and mortality of $\mathrm{BC}$ in patients with T2D [1-3]. Moreover, preclinical studies have described a variety of molecular mechanisms through which metformin indirectly or directly inhibits the growth of $\mathrm{BC}$ cells in vitro and in vivo [4-6].

The extensive clinical experience accumulated from patients with T2D prescribed metformin, together with its well characterized and modest toxicity profile $[7,8]$, has significantly shortened the clinical evaluation path of metformin in cancer prevention and treatment [9-11]. Accordingly, many clinical studies, including proof-of-principle studies in the prevention setting and phase 2 trials in the adjuvant and metastatic settings, have been planned and/or are currently under way to test the causal nature of the suggested correlation between metformin and clinical benefit in cancer.

To avoid overestimation of the potential effects of metformin in unselected populations of nondiabetic BC patients, preoperative translational studies are important to define specific BC subgroups more likely to benefit from metformin-based regimens. The neoadjuvant (preoperative) approach is known to maximize the capacity to test the benefits of drug combinations in the context of carefully designed clinical trials of early BC [12-15]. In this regard, a landmark retrospective study revealed that patients with $\mathrm{T} 2 \mathrm{D}$ and $\mathrm{BC}$ who received metformin and neoadjuvant chemotherapy appeared to have a higher $\mathrm{pCR}$ rate than did those not receiving metformin [16], a hypothesis-generating finding that warrants prospective evaluation.

Metformin has been shown to suppress both the tyrosine kinase activity and the expression of the human epidermal growth factor receptor 2 (HER2) protein in in vitro models of HER2-overexpressing $\mathrm{BC}$ cells [17-20], in addition to prolonging survival in HER2overexpressing transgenic BC mouse models [21]. Metformin treatment leads also to lower levels of circulating insulin and insulin-like growth factor (IGF-I), and to cell-autonomous inhibition of the mTOR pathway [22-25]. Such a multi-faceted capacity of metformin to target not only HER2 itself but also central mechanisms implicated in refractoriness to HER2-targeted therapies including both the IGF-I/mTOR signaling pathway and the self-renewal/proliferation of tumor-initiating cancer stem cells [26-30] provides strong experimental support to translate these pre-clinical findings into new metforminbased clinical management strategies that may benefit HER2-positive BC patients. However, most of the in-vitro models showing anti-HER2 activity of metformin used drug concentrations in the millimolar range, far higher than reported plasma metformin concentrations seen in diabetic patients treated with metformin [27, 31, 32], thereby leaving unanswered the question of whether metformin would have a clinical effect in patients suffering from HER2-positive BC. 
The open-label, multicenter, phase II randomized METTEN study [33] (EudraCT number 2011-00049030) evaluated the clinical activity, tolerability, and safety of adding metformin to neoadjuvant chemotherapy plus trastuzumab in operable, locally advanced, or inflammatory HER2-positive BC.

\section{RESULTS}

\section{Patient characteristics and disposition}

Between June 1, 2012 and March 17, 2016, 98 patients at 10 centers in Spain were recruited into the METTEN study. Due to slow accrual, the study closed prematurely with a reduced sample size after 84 of 244 planned patients were randomly assigned: 41 enrolled patients were allocated to the metformin group (arm A) and 43 patients to the non-metformin group (arm B).

Figure 1 shows the CONSORT diagram summarizing disposition of patients. Fourteen patients did not meet inclusion criteria and were not enrolled at the time of randomization. Nine patients in arm A and four patients in arm B failed to receive their allocated treatment, either due to treatment-related toxicity (eight patients in arm A and three in arm B) or they refused further followup or treatment (one in each arm) (Supplementary Table 2). Five patients were excluded from safety analyses because of informed consent withdrawal (two patients in arm A, one patient in arm B) or major protocol violation (one in each arm). The trial profile and treatment schedule is shown in Figure 2.

Patients and tumor characteristics of the modified ITT (mITT) population are summarized in Table 1. The baseline characteristics of the PP population (Supplementary Table 1) were similar to those of the mITT population. Most patients had T2 tumors (66\% and 59\% in arms A and B, respectively) and lymph node involvement ( $72 \%$ in arms A and B) at diagnosis. Within each stratum, no imbalances in terms of patient characteristics were observed across the two arms. Patients were stratified by age, extent of disease, and HR status.

\section{Responses and surgery}

The primary endpoint was the rate of $\mathrm{pCR}$ in breast and axilla in the efficacy analyzable PP population (twenty-nine patients in each arm). In arm A, 19/29 PP patients $(65.5 \%, 95 \% \mathrm{CI}: 47.3-80.1 \%)$ had a pCR versus $17 / 29$ PP patients $(58.6 \%, 95 \% \mathrm{CI}: 40.7-74.5 \%)$ in arm B. The minimum clinically important difference that could be detectable considering the available PP population size $(27.7 \% ; \alpha=0.15, \beta=0.20)$ was included in the upper limit $(31.8 \%)$ of the confidence interval of the difference of $\mathrm{pCR}$ rates between the metformin-containing and the standard reference arm. The combined rates of $\mathrm{pCR}$ (ypT0/is, ypN0) and near-pCR, the latter defined as presence of infiltrating residual disease of less than $5 \mathrm{~mm}$ and node negativity (ypT1aN0), were 79.3\% (95\% CI: 61.6-90.2\%) in arm A and 72.4\% (95\% CI: 54.3-85.3\%) in arm B (Table 2).

Breast-conserving surgery (BCS) was possible in $79.3 \%$ of patients in arm A, which was apparently superior to the $58.6 \%$ achieved in arm B $(P=0.089$, Table 2). Among patients undergoing BCS, 91.3\% achieved a $\mathrm{pCR} /$ nearpCR in the metformin arm versus $76.5 \%$ in the reference arm (Table 2).

Supplementary Table 3 summarizes the pCR and surgery analyses performed for the mITT population. In Arm A, 19/38 mITT patients (50\%, 95\% CI: 34.8-65.1\%) had a pCR versus $23 / 41$ mITT patients $(56.1 \%, 95 \% \mathrm{CI}$ : $41.0-70.1 \%$ ) in arm B. BCS was possible in $78.4 \%$ of mITT patients in arm A, which was superior to the $61.0 \%$ achieved in arm B $(P=0.096)$.

\section{Prediction of response}

Although the study was underpowered (42\%) because of a small number of patients evaluable for the primary endpoint, we performed an exploratory analysis to describe the distribution of pCR rates between arms in the analyzable PP efficacy population. Such exploratory analysis showed no differences between the two arms (odds ratio [OR] 1.34 [95\% CI: 0.46-3.89], $P=0.589$; Table 3). The analysis performed in the mITT population similarly showed no differences between the two arms (OR 0.78 [95\% CI: 0.32-1.90], $P=0.588$; Supplementary Table 4).

In univariable analysis for predetermined factors predicting a pCR in the two arms, solely $\mathrm{T} 2$ and $\mathrm{PgR}$ negativity $(P=0.021)$ appeared to associate with the probability of achieving pCR (OR 3.12 [95\% CI: 1.029.48] and 3.76 [95\% CI: 1.23-11.51], respectively) in the efficacy analyzable PP population (Table 3 ). In bivariate analysis, PgR negativity seemed to show predictive capacity irrespective of the arm in which the patients were randomized (Supplementary Table 5). In the mITT population, a similar association appeared to occur between PgR negativity and the probability of achieving $\mathrm{pCR}$ in uni- and bivariate analysis (Supplementary Tables 4 and 6 , respectively).

In multivariable analysis, $\mathrm{PgR}$ negativity no longer associated with the probability of achieving a pCR (data not shown). Supplementary Tables 7 and 8 summarizes how the pCR rates in both arms appeared to remain unchanged according to hormonal receptor status in the PP and mITT populations, respectively.

\section{Circulating metformin}

We assessed serum concentrations of metformin in a subgroup of twenty-two patients using HPLC-ESI-QTOF-MS (Figure 3). Inadequate blood samples were drawn in 
two patients and were excluded from the analysis. The mean concentration was determined to be $6.2 \mu \mathrm{mol} / \mathrm{L}$ (95\% CI: 3.6-8.8) with a range from $0.1 \mu \mathrm{mol} / \mathrm{L}$ to $21.1 \mu \mathrm{mol} / \mathrm{L}$. We detected slightly higher levels of circulating metformin in patients achieving pCR (mean $7.1 \mu \mathrm{mol} / \mathrm{L}$; $95 \% \mathrm{CI}: 3.0-11.1)$ than in those belonging to the non-responders group (mean $4.7 \mu \mathrm{mol} / \mathrm{L} ; 95 \% \mathrm{CI}$ : 2.7-6.7; $P=0.757$ ). Supplementary Figure 1 shows the distribution of serum metformin through concentrations as a function of the time of blood sampling/metformin intake.

\section{Compliance with treatment and toxicity}

The most frequently occurring AEs (290 in arm A and 306 in arm B) were fatigue, diarrhea, nausea, alopecia, sensory neuropathy, mucositis, neutropenia, and elevated AST/ALT (Table 4, Supplementary Table 9). Most AEs were of grades 1 and 2 (92.1\% in arm A and $95.8 \%$ in arm B; Table 4, Supplementary Table 9). The majority of the most frequent AEs were deemed possibly related to study treatment. The overall incidence of AEs of grade $\geq 3$ ranged from $7.9 \%(23 / 290$ events $)$ in arm A to $4.3 \%$ $(13 / 306$ events) in arm B; the most common of which were neutropenia (7/38 patients in arm A and 5/41 patients in arm B) and diarrhea (5 and 0, respectively; Table 4).

The number of serious AEs requiring hospitalization was three in arm A and two in arm B (details are summarized in the Supplementary Table 10). No treatment-related deaths occurred.

\section{Cardiac tolerability}

Table 5 shows baseline LVEF values and changes during neoadjuvant treatment in the two study arms. LVEF dropped below baseline during the treatment period in both arms; however, mean and median decreases were no more than 5\% (Supplementary Table 11). Although the profiles of LVEF changes over time were similar between arms (Figure 4), only one (2.9\%) patient in arm A and six $(15 \%)$ in arm B exhibited asymptomatic decreases in LVEF below the institutional lower limit (50\%) and $>10 \%$ from baseline at week $12(P=0.032$; Table 5$)$. At the treatment end, none $(0 \%)$ of the patients in arm $A$ and three $(8.1 \%)$ in arm B presented decreases in LVEF $(P=0.409$; Table 5). Only one patient $(2.7 \%)$ in arm B experienced symptomatic heart failure.

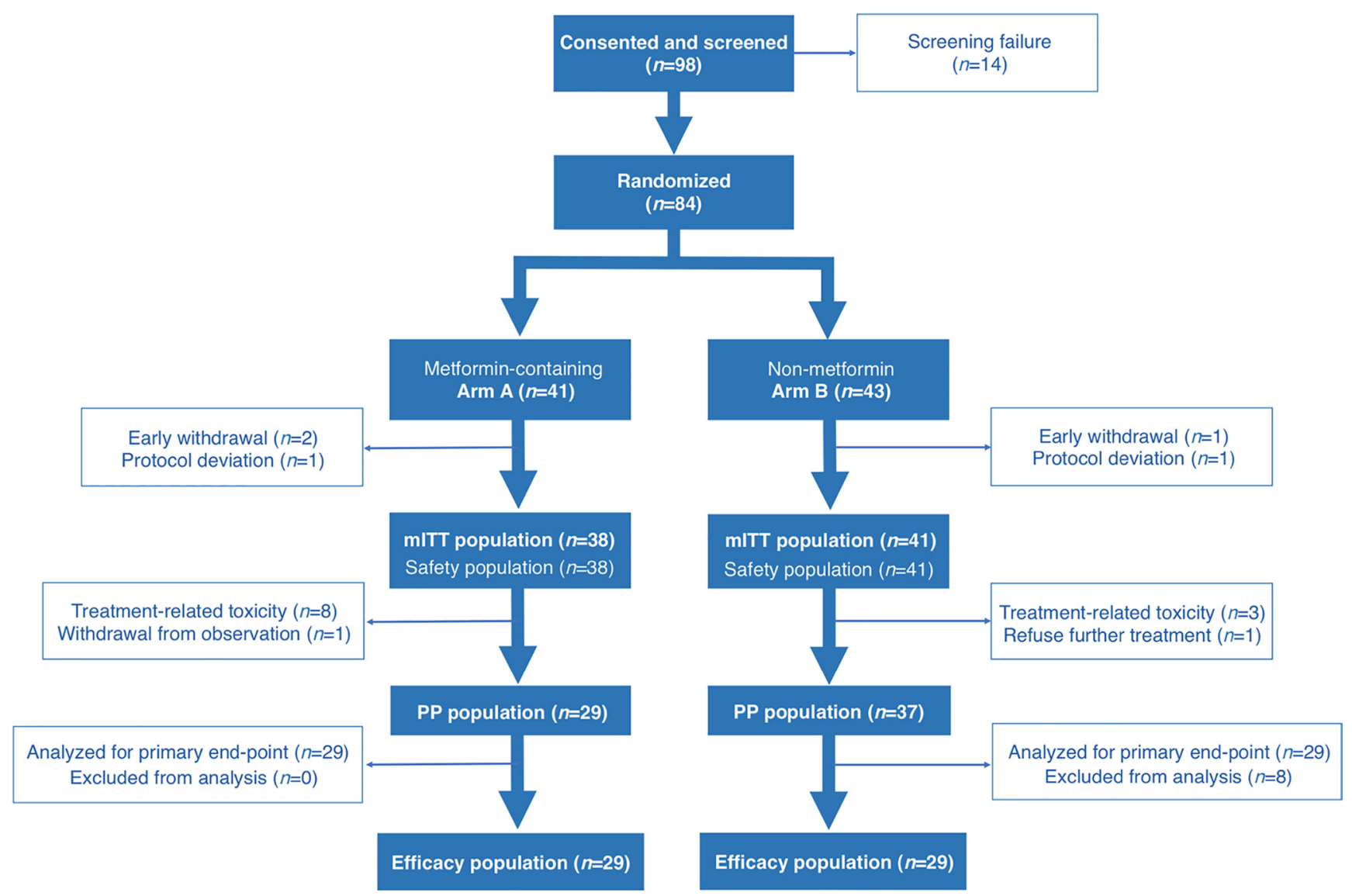

Figure 1: METTEN trial profile. CONSORT diagram summarizing disposition of patients in the METTEN study. (mITT: modified intention-to-treat; PP: per-protocol). 


\section{DISCUSSION}

The METTEN study compared conventional chemotherapy plus trastuzumab with the combination of metformin and chemotherapy plus trastuzumab in the neoadjuvant setting for treatment of early HER2-positive BC.

Assessment of pCR using the definition ypT0/ is, ypN0 showed that the two treatment regimens were highly active, with $\mathrm{pCR}$ rates ranging from $58.6 \%$ in the reference arm to $65.5 \%$ in the metformin arm. Such high pCR rates in the small sample size of the METTEN study were consistent with those originally reported in the MD Anderson Cancer Center trial (55-65\%) [34, 35] and with our previous experience $(61.4 \%)$ of concurrent trastuzumab plus weekly paclitaxel-FEC as primary therapy for HER2-positive $\mathrm{BC}$ in everyday clinical practice [36]. Although the $\mathrm{pCR}$ rates in our study were numerically higher than those generally found in larger randomized phase III trials such as the NOAH [37], the GeparQuattro [38], the HannaH [39], or the Cortazar metaanalysis of neoadjuvant $\mathrm{BC}$ trials [13], which reported pCR rates up to $40 \%$, such differences were most likely due to differences in study populations.
The numerically higher $\mathrm{pCR}$ rate observed in the PP population receiving the neoadjuvant metformin did not reach statistical significance in our study. However, it should be acknowledged that the trial was closed before the first scheduled interim analysis due to slow recruitment. As a result, a formal statistical comparison of treatment arms in the reported efficacy/PP population was statistically underpowered, and the efficacy analysis should be considered purely exploratory. Evaluation of long-term outcome data such as 5-year DFS together with correlative biological studies evaluating proliferation markers (e.g., Ki-67) and selected predictive factors of response to neoadjuvant treatment in HER2-positive BC (e.g., EGFR and PTEN) are currently underway in our laboratory to adequately appraise whether those patients who received neoadjuvant metformin might gain an additional survival benefit and the mechanisms involved [35, 40-44]. Although a higher BCS rate was observed in patients receiving additional metformin, breast conservation is known to depend on multiple parameters including breast size, tumor location, presence of DCIS, the multifocality of the lesion, or patient willingness [45], thus making it challenging to attribute such differences to a true clinico-molecular benefit in those patients receiving neoadjuvant metformin.

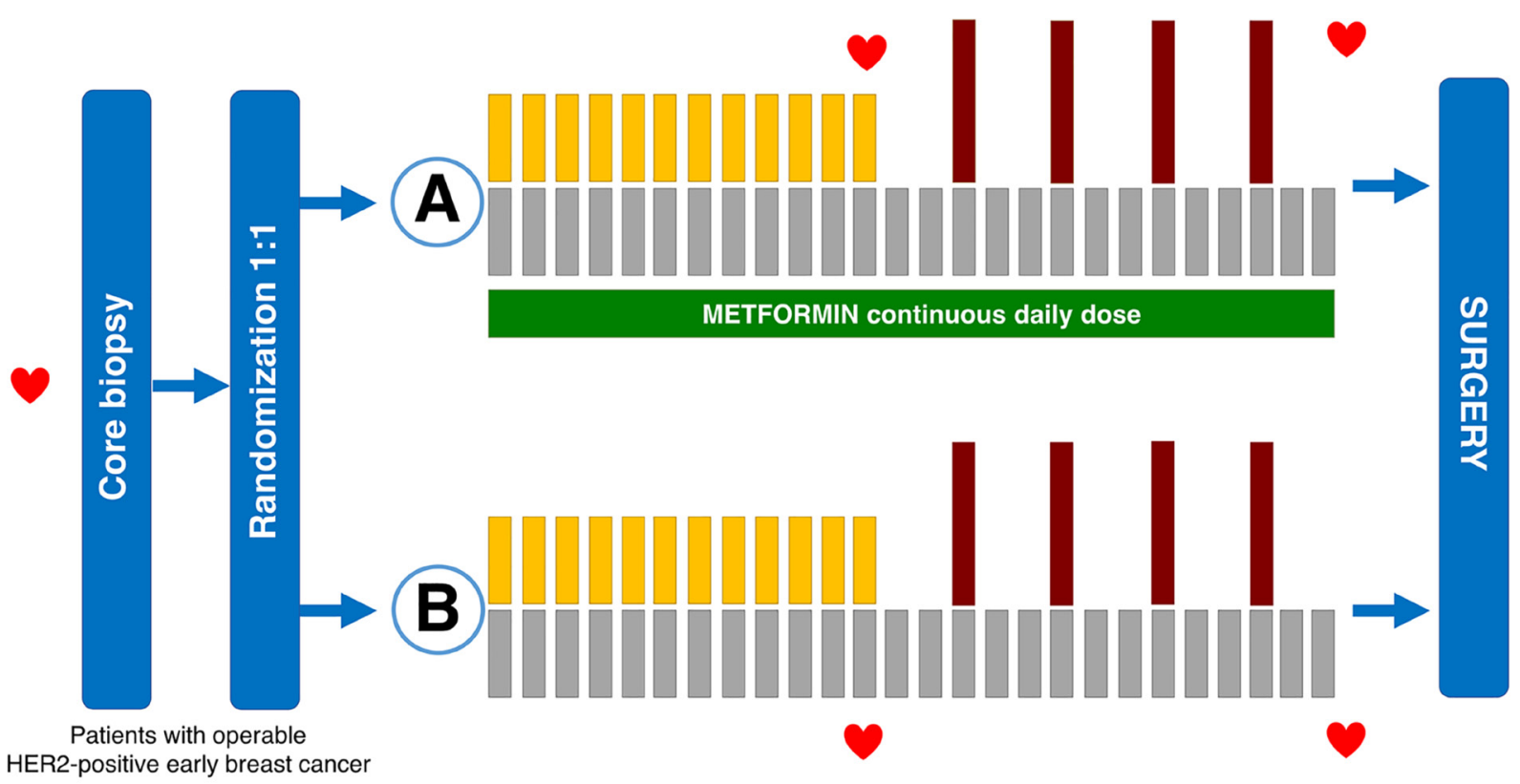

HER2-positive early breast cancer

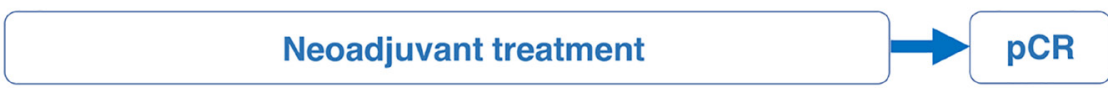

Paclitaxel $80 \mathrm{mg} / \mathrm{m}^{2}$ once weekly

Flurouracil $600 \mathrm{mg} / \mathrm{m}^{2}$

Trastuzumab $4 \mathrm{mg} / \mathrm{Kg}$, loading dose $2 \mathrm{mg} / \mathrm{kg}$ once weekly

Metformin 1,700 mg/day, $850 \mathrm{mg} /$ tablet twice a day

Epirubicin $75 \mathrm{mg} / \mathrm{m}^{2}$

LVEF

Cyclophosphamide $600 \mathrm{mg} / \mathrm{m}^{2}$ every 3 weeks

Figure 2: METTEN study design. Stratification factors: age, extent of disease (cT2 cN0-1 vs $\geq$ cT3 or $\geq \mathrm{cN} 2$ ), and hormone receptor (HR) status. Primary endpoint: pCR in breast and axilla. (HER2, human epidermal growth factor receptor; LVEF, left ventricular ejection fraction; pCR, pathological complete response). 
Table 1: Baseline patient demographic and tumor characteristics for the mITT population

\begin{tabular}{|c|c|c|c|}
\hline & $\operatorname{Arm} \mathrm{A}(N=38)$ & $\operatorname{Arm~B}(N=41)$ & Pvalue \\
\hline Age (years) & & & 0.780 \\
\hline$<50$ & $22(57.9 \%)$ & $25(61.0 \%)$ & \\
\hline$\geq 50$ & $16(42.1 \%)$ & $16(39.0 \%)$ & \\
\hline Mean \pm SD (range) & $47.2 \pm 10.6(26-75)$ & $48.0 \pm 11.5(23-72)$ & 0.754 \\
\hline Menopausal status & & & 0.818 \\
\hline Post & $14(36.8 \%)$ & $17(41.5 \%)$ & \\
\hline Pre & $24(63.2 \%)$ & $24(58.8 \%)$ & \\
\hline \multicolumn{4}{|l|}{ Body weight (kg) } \\
\hline Mean \pm SD (range) & $64.6 \pm 8.7(45.3-89.0)$ & $65.2 \pm 9.4(48.0-83.0)$ & 0.289 \\
\hline Body mass index (BMI) & & & 0.564 \\
\hline$<25$ & $21(55.3 \%)$ & $20(48.8 \%)$ & \\
\hline$\geq 25$ (overweight) & $17(44.7 \%)$ & $21(51.2 \%)$ & \\
\hline Clinical tumor status & & & 0.681 \\
\hline cT2 & $25(65.8 \%)$ & $26(63.4 \%)$ & \\
\hline cT3 & $12(31.6 \%)$ & $10(24.4 \%)$ & \\
\hline cT4a & $0(0.0 \%)$ & $1(2.4 \%)$ & \\
\hline $\mathrm{cT} 4 \mathrm{~b}$ & $1(2.6 \%)$ & $3(7.3 \%)$ & \\
\hline cT4d & $0(0.0 \%)$ & $1(2.4 \%)$ & \\
\hline Clinical nodal Stage & & & 0.445 \\
\hline $\mathrm{cN} 0$ & $9(23.7 \%)$ & $13(31.7 \%)$ & \\
\hline $\mathrm{cN} 1$ & $24(63.2 \%)$ & $20(48.8 \%)$ & \\
\hline $\mathrm{cN} 2$ & $1(2.6 \%)$ & $4(9.7 \%)$ & \\
\hline $\mathrm{cN} 3$ & $4(10.5 \%)$ & $4(9.7 \%)$ & \\
\hline Hormone receptor status & & & 0.477 \\
\hline ER and/or PgR positive & $19(50.0 \%)$ & $24(58.5 \%)$ & \\
\hline ER and PR negative & $19(50.0 \%)$ & $17(41.5 \%)$ & \\
\hline Tumor grade & & & 0.272 \\
\hline G1 & $2(7.1 \%)$ & $0(0.0 \%)$ & \\
\hline $\mathrm{G} 2$ & $12(42.9 \%)$ & $18(54.5 \%)$ & \\
\hline G3 & $14(50.0 \%)$ & $15(45.5 \%)$ & \\
\hline Unknown & 10 & 8 & \\
\hline Baseline LVEF (\%) & & & 0.755 \\
\hline$[50-55]$ & $3(10.3 \%)$ & $2(6.3 \%)$ & \\
\hline$[55-60]$ & $7(24.1 \%)$ & $6(18.8 \%)$ & \\
\hline$[60-65]$ & $8(27.6 \%)$ & $13(40.6 \%)$ & \\
\hline$[65-70]$ & $11(37.9 \%)$ & $11(34.4 \%)$ & \\
\hline$\geq 70$ & 9 & 9 & \\
\hline Type of programmed surgery & & & 0.171 \\
\hline Breast-conserving & $26(76.5 \%)$ & $24(61.5 \%)$ & \\
\hline Mastectomy & $8(23.5 \%)$ & $15(38.5 \%)$ & \\
\hline Unknown & 4 & 2 & \\
\hline
\end{tabular}

LVEF: Left Ventricular Ejection Fraction. 


\begin{tabular}{|c|c|c|c|}
\hline & $\operatorname{Arm} \mathrm{A}(N=29)$ & $\operatorname{Arm} B(N=29)$ & $P$ value \\
\hline \multicolumn{4}{|l|}{ Type of surgery } \\
\hline Mastectomy & $6(20.7 \%)$ & $12(41.4 \%)$ & 0.089 \\
\hline Breast-conserving surgery & $23(79.3 \%)$ & $17(58.6 \%)$ & \\
\hline \multicolumn{4}{|l|}{ Response } \\
\hline $\mathrm{pCR}$ & & & 0.588 \\
\hline No & $10(34.5 \%)$ & $12(41.4 \%)$ & \\
\hline Yes & $19(65.5 \%)$ & $17(58.6 \%)$ & \\
\hline $\mathrm{pCR}+$ near $\mathrm{pCR}$ & & & 0.539 \\
\hline No & $6(20.7 \%)$ & $8(27.6 \%)$ & \\
\hline Yes & $23(79.3 \%)$ & $21(72.4 \%)$ & \\
\hline \multicolumn{4}{|l|}{ Type of surgery $\&$ response } \\
\hline \multicolumn{4}{|l|}{ Mastectomy $(N=18)$} \\
\hline $\mathrm{pCR}$ & & & 0.620 \\
\hline No & $4(66.7 \%)$ & $5(41.7 \%)$ & \\
\hline Yes & $2(33.3 \%)$ & $7(58.3 \%)$ & \\
\hline $\mathrm{pCR}+$ near $\mathrm{pCR}$ & & & 0.321 \\
\hline No & $4(66.7 \%$ & $4(33.3 \%)$ & \\
\hline Yes & $2(33.3 \%)$ & $8(66.7 \%)$ & \\
\hline \multicolumn{4}{|c|}{ Breast-conserving surgery $(N=40)$} \\
\hline $\mathrm{pCR}$ & & & 0.314 \\
\hline No & $6(26.1 \%)$ & $7(41.2 \%)$ & \\
\hline Yes & $17(73.9 \%)$ & $10(58.8 \%)$ & \\
\hline $\mathrm{pCR}+$ near $\mathrm{pCR}$ & & & 0.373 \\
\hline No & $2(8.7 \%)$ & $4(23.5 \%)$ & \\
\hline Yes & $21(91.3 \%)$ & $13(76.5 \%)$ & \\
\hline
\end{tabular}

Data from the Asian Medical Center Breast Cancer Database concluded that diabetic patients receiving metformin when $\mathrm{BC}$ is diagnosed show a better prognosis only if they had HR-positive, HER2-positive tumors [46]. Moreover, an analysis of the ALTTO Phase III randomized trial, which assigned patients with HER2-positive BC to receive 1 year of trastuzumab alone, lapatinib alone, their sequence, or their combination, found that metformin exerted a statistically-significant beneficial effect in those patients with diabetes who had primary HER2-positive and HR-positive BC [47]. Neoadjuvant trials with antiHER2 therapy have demonstrated a HR status-related prognostic value after achieving a $\mathrm{pCR}$, with a higher survival effect in the HR-negative group than in the HRpositive group [48]. In the METTEN study, a higher percentage of PgR-negative patients achieved a pCR in both arms, thus confirming the notion that the likelihood of response according to HR status is an intrinsic characteristic of HER2-positive tumors [49, 50]. However, we failed to clarify the actual predictive value of pCR in the metformin-containing arm according to HR status.
After hepatic uptake, the plasma concentration of metformin is reduced to $5-20 \mu \mathrm{mol} / \mathrm{L}$ after oral doses of $0.5-1.5 \mathrm{~g}$ metformin in humans with a mean plasma halflife of about $20 \mathrm{~h}[6,31,51]$. Our analytical determination of serum metformin confirmed that treatment of non-diabetic HER 2 + BC patients with oral metformin $(850 \mathrm{mg}$ twicedaily) for 24 weeks produced blood levels of circulating metformin (approx. $7 \mu \mathrm{mol} / \mathrm{L}$ ) equivalent to those generally achieved in diabetic patients at the usual clinical doses and schedules [27, 31, 32]. Although systemic exposure of metformin seemed more elevated in those patients achieving a $\mathrm{pCR}$ than in non-responder patients, two outliers within the responder group appeared to drive such trend that failed to reach statistical significance. Moreover, we measured circulating concentrations of metformin in blood samples that were not strictly timed in terms of hours since preceding oral dose [51] and, therefore, our data need to be viewed cautiously in terms of any association between achieved serum concentration and probability of $\mathrm{pCR}$.

One major concern regarding the utility of metformin is its known ability to induce gastrointestinal upset 
Table 3: Univariable analysis of factors associated with a pCR in the PP efficacy population

\begin{tabular}{|c|c|c|c|c|}
\hline Category & No pCR $N(\%)$ & $\operatorname{pCR} N(\%)$ & OR (95\% CI) & $P$ value \\
\hline \multicolumn{5}{|l|}{ Arm } \\
\hline B & $12(41.4 \%)$ & $17(58.6 \%)$ & 1 & \\
\hline A & $10(34.5 \%)$ & $19(65.5 \%)$ & $1.34(0.46-3.89)$ & 0.589 \\
\hline \multicolumn{5}{|l|}{ Age (years) } \\
\hline$<50$ & $16(47.1 \%)$ & $18(52.9 \%)$ & & \\
\hline$\geq 50$ & $6(25.0 \%)$ & $18(75.0 \%)$ & $2.67(0.85-8.37)$ & 0.093 \\
\hline \multicolumn{5}{|c|}{ Clinical tumor stage } \\
\hline$\geq \mathrm{T} 3$ & $12(52.2 \%)$ & $11(47.8 \%)$ & 1 & \\
\hline $\mathrm{T} 2$ & $10(28.6 \%)$ & $25(71.4 \%)$ & $3.12(1.02-9.48)$ & 0.073 \\
\hline \multicolumn{5}{|c|}{ Clinical nodal status } \\
\hline$N \geq 2$ & $4(40.0 \%)$ & $6(60.0 \%)$ & 1 & \\
\hline N0-1 & $18(37.5 \%)$ & $30(62.5 \%)$ & $1.11(0.28-4.48)$ & 0.882 \\
\hline \multicolumn{5}{|l|}{ ER } \\
\hline Positive & $13(43.3 \%)$ & $17(56.7 \%)$ & 1 & \\
\hline Negative & $9(32.1 \%)$ & $19(67.9 \%)$ & $1.61(0.55-4.72)$ & 0.381 \\
\hline \multicolumn{5}{|l|}{ PgR } \\
\hline Positive & $13(56.5 \%)$ & $10(43.5 \%)$ & 1 & \\
\hline Negative & $9(25.7 \%)$ & $26(74.3 \%)$ & $3.76(1.23-11.51)$ & 0.021 \\
\hline \multicolumn{5}{|l|}{ HR status } \\
\hline Positive & $14(45.2 \%)$ & $17(54.8 \%)$ & 1 & \\
\hline Negative & $8(29.6 \%)$ & $19(79.4 \%)$ & $1.96(0.66-5.80)$ & 0.227 \\
\hline
\end{tabular}

OR, odds ratio.

and diarrhea, which might limit patient compliance, particularly when combined with cytotoxic chemotherapy [52]. The METTEN study confirms that metformin is likely a tolerable and safe addition to current therapy regimens $[53,54]$. From the perspective of tolerability, it should be noted that the dropout rate in the metformin arm was much lower than the expected $25 \%$; only $13 \%$ (5 out of 38) of patients withdrew because of metformin-related gastrointestinal upset and diarrhea, whereas more than 75\% (29 out of 38) patients completed the 6-month intervention with metformin as part of a complex neoadjuvant combination. The safety of the triple regimen of metformin, chemotherapy, and trastuzumab was similar to that of chemotherapy and trastuzumab. None of the three serious AEs in arm A was deemed to be exclusively metforminrelated. Because residual disease after neoadjuvant therapy is a poor prognostic factor [55], it would be relevant to evaluate whether upregulated mitochondrial oxidative phosphorylation (OXPHOS) - a primary target of metformin- is part of the metabolic shifts that drive tumor recurrence in residual $\mathrm{BC}$ [56], thereby allowing metformin to be considered as a safe candidate to treat OXPHOSdependent residual $\mathrm{BC}$ disease.

When we evaluated the cardiac tolerability of metformin given in the triple regimen, metformin did not increase the baseline rate of cardiac dysfunction observed in the reference arm. Moreover, by assessing the trajectories of LVEF decline over time, we observed a small trend towards a lower number of asymptomatic cardiac events in the metformin-containing arm. HER2 signaling is involved in myocardial homeostasis and its inhibition may explain the increased incidence of cardiomyopathy associated with the treatment with trastuzumab, particularly in those patients exposed to cardiotoxic chemotherapies such as anthracyclines $[57,58]$. Trastuzumab-induced cardiomyopathy relates, at least in part, to its inability to activate pro-survival catabolic pathways through AMP-activated protein kinase (AMPK) in cardiac cells [59, 60]. Because metformin treatment has been shown to improve cardiovascular function and reduce cardiovascular risk in diabetic patients through the activation of AMPK [61]-a cellautonomous mechanism that also underlies the activity of metformin as an anticancer drug [4-6]- larger and longerterm studies evaluating biomarkers of cardiotoxicity in trastuzumab-exposed oncologic populations will be needed to clarify whether metformin induces AMPK (and downstream catabolic) signaling upon trastuzumabinduced metabolic dysregulation in cardiomyocytes [20,62]. 
During recruitment, the findings of the phase II NeoSphere [49] and TRYPHAENA trials [63], together with the impressive survival benefits for women with HER2-positive metastatic $\mathrm{BC}$ receiving pertuzumab along with trastuzumab in the phase III CLEOPATRA study [64], led to the accelerated approval of pertuzumab by the FDA in September 2013 and the European Medicines Agency in July 2015 for use in combination with trastuzumab plus chemotherapy for neoadjuvant treatment of patients with HER2-positive locally advanced, inflammatory, or earlystage BC. Consequently, ethical issues arose during the METTEN study trial based on the recommended standard of care supported by national and international guidelines with a neoadjuvant combination of taxane-containing chemotherapy and a dual blockade of trastuzumab and pertuzumab. Moreover, we cannot exclude the possibility that a rejection bias might exist against the repurposing of generic non-cancer metformin as oncological treatment when confronted to commercially developed anti-cancer drugs [65].

Two previous randomized phase II trials have shown that metformin in combination with systemic therapy fails to significantly improve outcomes in patients with advanced/metastatic pancreatic cancer $[66,67]$. These studies by Kordes [66] and Reni [67] intended very ambitious clinical targets in terms of overall survival (from $50 \%$ to $75 \%$ at 6 months) and progression-free survival (from $50 \%$ to $70 \%$ at 6 months), respectively.
Because the METTEN trial failed to identify also a large difference, i.e., a $25 \%$ increase over an expected pCR of $60 \%$ with chemotherapy plus trastuzumab before a phase 3 trial could be justified, it might be tempting to suggest that testing against high bars of clinical outcome endpoints instead of using a priori non-inferiority trial designs should be cautiously considered before concluding that studies using metformin for treating cancer should be abandoned. Moreover, negative results of first-generation cancer trials using metformin at the same dose and route of administration that in diabetic patients would not rule out the clinical utility of biguanides other than metformin (e.g., phenformin) or non-conventional routes for administering biguanides if previously optimized for oncology indications [68-71]. However, as we did not achieve the target number of patients to power the study, we cannot be certain whether the lack of significant difference between the two arms of the METTEN trial is a type II error or reflects a true lack of efficacy for the metformin-based neoadjuvant strategy in early HER2-positive BC. Beyond general considerations such as the need to consolidate prognostic, predictive, and pharmacodynamic factors of the metabolic response to metformin for selecting subsets of patients most likely to benefit from metformin treatment, mature results from large, randomized studies, such as the NCIC CTG MA.32, the most advanced adjuvant trial investigating the effects of metformin versus placebo on invasive DFS and other
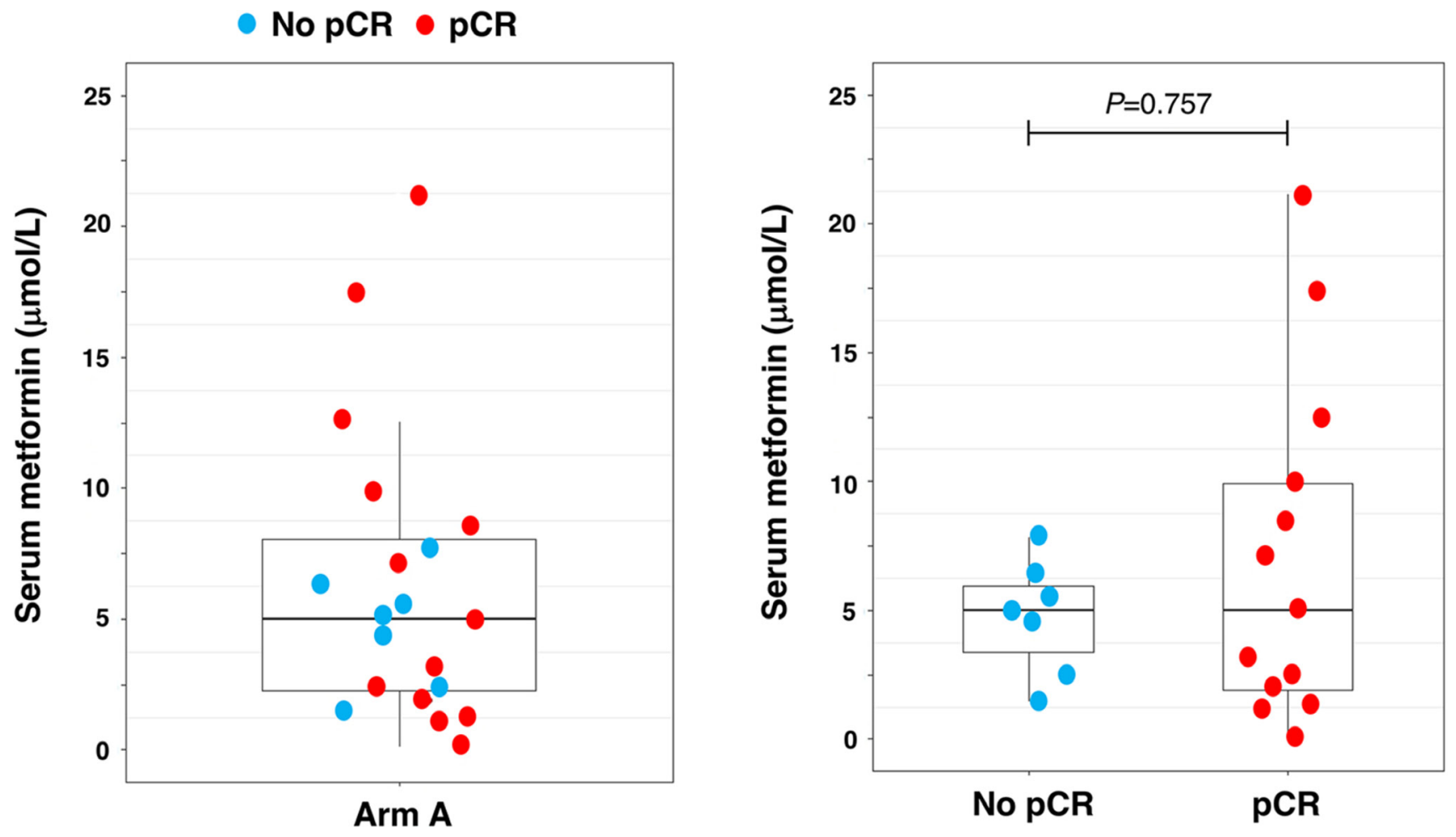

Figure 3: Circulating serum metformin. Box plots indicating median (black lines within the boxes), interquartile ranges, whiskers and ranges for post-treatment levels of circulating serum metformin $(\mu \mathrm{mol} / \mathrm{L} ; N=20)$. (pCR: pathological complete response). 
Table 4: Cardiac and most common adverse events reported as possibly, probably, or definitely related to treatment in the mITT population

\begin{tabular}{|c|c|c|c|c|c|c|c|c|}
\hline & \multicolumn{4}{|c|}{$\operatorname{Arm} A(N=38)$} & \multicolumn{4}{|c|}{$\operatorname{Arm~B}(N=41)$} \\
\hline & Grade 1 & Grade 2 & Grade 3 & Grade 4 & Grade 1 & Grade 2 & Grade 3 & Grade 4 \\
\hline \multicolumn{9}{|l|}{ Hematological toxicity } \\
\hline Anemia & $3(7.9 \%)$ & $3(7.9 \%)$ & $2(5.3 \%)$ & $0(0.0 \%)$ & $2(4.9 \%)$ & $4(9.8 \%)$ & $0(0.0 \%)$ & $0(0.0 \%)$ \\
\hline Thrombocytopenia & $0(0.0 \%)$ & $0(0.0 \%)$ & $1(2.6 \%)$ & $0(0.0 \%)$ & $0(0.0 \%)$ & $0(0.0 \%)$ & $0(0.0 \%)$ & $0(0.0 \%)$ \\
\hline Leukopenia & $3(7.9 \%)$ & $0(0.0 \%)$ & $0(0.0 \%)$ & $0(0.0 \%)$ & $3(7.3 \%)$ & $0(0.0 \%)$ & $0(0.0 \%)$ & $0(0.0 \%)$ \\
\hline Neutropenia & $2(5.3 \%)$ & $4(10.5 \%)$ & $5(13.2 \%)$ & $2(5.3 \%)$ & $4(9.8 \%)$ & $2(4.9 \%)$ & $4(9.8 \%)$ & $1(2.4 \%)$ \\
\hline Febrile Neutropenia & $0(0.0 \%)$ & $0(0.0 \%)$ & $1(2.6 \%)$ & $1(2.6 \%)$ & $0(0.0 \%)$ & $0(0.0 \%)$ & $2(4.9 \%)$ & $0(0.0 \%)$ \\
\hline \multicolumn{9}{|l|}{ Gastrointestinal disorders } \\
\hline Diarrhea & $18(47.4 \%)$ & $5(13.2 \%)$ & $5(13.2 \%)$ & $0(0.0 \%)$ & $12(29.3 \%)$ & $0(0.0 \%)$ & $0(0.0 \%)$ & $0(0.0 \%)$ \\
\hline Constipation & $4(10.5 \%)$ & $0(0.0 \%)$ & $0(0.0 \%)$ & $0(0.0 \%)$ & $2(4.9 \%)$ & $1(2.4 \%)$ & $0(0.0 \%)$ & $0(0.0 \%)$ \\
\hline Nausea & $14(36.8 \%)$ & $4(10.5 \%)$ & $1(2.6 \%)$ & $0(0.0 \%)$ & $12(29.3 \%)$ & $4(9.8 \%)$ & $1(2.4 \%)$ & $0(0.0 \%)$ \\
\hline Vomiting & $12(31.6 \%)$ & $5(13.2 \%)$ & $0(0.0 \%)$ & $0(0.0 \%)$ & $4(9.8 \%)$ & $1(2.4 \%)$ & $1(2.4 \%)$ & $0(0.0 \%)$ \\
\hline Mucositis & $13(34.2 \%)$ & $1(2.6 \%)$ & $0(0.0 \%)$ & $0(0.0 \%)$ & $12(29.3 \%)$ & $5(12.2 \%)$ & $0(0.0 \%)$ & $0(0.0 \%)$ \\
\hline Dyspepsia & $2(5.3 \%)$ & $0(0.0 \%)$ & $0(0.0 \%)$ & $0(0.0 \%)$ & $2(4.9 \%)$ & $0(0.0 \%)$ & $0(0.0 \%)$ & $0(0.0 \%)$ \\
\hline Pyrosis & $3(7.9 \%)$ & $0(0.0 \%)$ & $0(0.0 \%)$ & $0(0.0 \%)$ & $6(14.6 \%)$ & $1(2.4 \%)$ & $0(0.0 \%)$ & $0(0.0 \%)$ \\
\hline Epigastric Pain & $6(15.8 \%)$ & $0(0.0 \%)$ & $0(0.0 \%)$ & $0(0.0 \%)$ & $5(12.2 \%)$ & $0(0.0 \%)$ & $0(0.0 \%)$ & $0(0.0 \%)$ \\
\hline \multicolumn{9}{|l|}{ General disorders } \\
\hline Fatigue & $22(57.9 \%)$ & $8(21.1 \%)$ & $1(2.6 \%)$ & $0(0.0 \%)$ & $23(56.1 \%)$ & $11(26.8 \%)$ & $0(0.0 \%)$ & $0(0.0 \%)$ \\
\hline Headache & $2(5.3 \%)$ & $1(2.6 \%)$ & $0(0.0 \%)$ & $0(0.0 \%)$ & $4(9.8 \%)$ & $2(4.9 \%)$ & $0(0.0 \%)$ & $0(0.0 \%)$ \\
\hline Fever & $1(2.6 \%)$ & $0(0.0 \%)$ & $0(0.0 \%)$ & $0(0.0 \%)$ & $2(4.9 \%)$ & $0(0.0 \%)$ & $0(0.0 \%)$ & $0(0.0 \%)$ \\
\hline \multicolumn{9}{|l|}{ Vascular disorders } \\
\hline Edema & $2(5.3 \%)$ & $0(0.0 \%)$ & $0(0.0 \%)$ & $0(0.0 \%)$ & $4(9.8 \%)$ & $0(0.0 \%)$ & $0(0.0 \%)$ & $0(0.0 \%)$ \\
\hline Hypertension & $0(0.0 \%)$ & $0(0.0 \%)$ & $0(0.0 \%)$ & $0(0.0 \%)$ & $2(4.9 \%)$ & $0(0.0 \%)$ & $0(0.0 \%)$ & $0(0.0 \%)$ \\
\hline \multicolumn{9}{|l|}{ Skin disorders } \\
\hline Alopecia & $5(13.2 \%)$ & $12(31.6)$ & $0(0.0 \%)$ & $0(0.0 \%)$ & $9(22.0 \%)$ & $9(22.0 \%)$ & $0(0.0 \%)$ & $0(0.0 \%)$ \\
\hline Rash & $7(18.4 \%)$ & $0(0.0 \%)$ & $0(0.0 \%)$ & $0(0.0 \%)$ & $4(9.8 \%)$ & $2(4.9 \%)$ & $0(0.0 \%)$ & $0(0.0 \%)$ \\
\hline Erythema & $2(5.3 \%)$ & $0(0.0 \%)$ & $0(0.0 \%)$ & $0(0.0 \%)$ & $4(9.8 \%)$ & $0(0.0 \%)$ & $1(2.4 \%)$ & $0(0.0 \%)$ \\
\hline Pruritus & $4(10.5 \%)$ & $0(0.0 \%)$ & $0(0.0 \%)$ & $0(0.0 \%)$ & $2(4.9 \%)$ & $0(0.0 \%)$ & $0(0.0 \%)$ & $0(0.0 \%)$ \\
\hline Nail changes & $3(7.9 \%)$ & $2(5.3 \%)$ & $0(0.0 \%)$ & $0(0.0 \%)$ & $4(9.8 \%)$ & $2(4.9 \%)$ & $0(0.0 \%)$ & $0(0.0 \%)$ \\
\hline $\begin{array}{l}\text { Toxicodermic reaction } \\
\text { to chemotherapy }\end{array}$ & $0(0.0 \%)$ & $0(0.0 \%)$ & $0(0.0 \%)$ & $0(0.0 \%)$ & $0(0.0 \%)$ & $0(0.0 \%)$ & $1(2.4 \%)$ & $0(0.0 \%)$ \\
\hline Rosacea & $0(0.0 \%)$ & $0(0.0 \%)$ & $0(0.0 \%)$ & $0(0.0 \%)$ & $0(0.0 \%)$ & $0(0.0 \%)$ & $1(2.4 \%)$ & $0(0.0 \%)$ \\
\hline Skin toxicity & $2(5.3 \%)$ & $0(0.0 \%)$ & $0(0.0 \%)$ & $0(0.0 \%)$ & $3(7.3 \%)$ & $2(4.9 \%)$ & $0(0.0 \%)$ & $0(0.0 \%)$ \\
\hline \multicolumn{9}{|l|}{ Metabolism disorders } \\
\hline Anorexia & $4(10.5 \%)$ & $0(0.0 \%)$ & $0(0.0 \%)$ & $0(0.0 \%)$ & $2(4.9 \%)$ & $1(2.4 \%)$ & $0(0.0 \%)$ & $0(0.0 \%)$ \\
\hline Hypercalcemia & $1(2.6 \%)$ & $0(0.0 \%)$ & $0(0.0 \%)$ & $0(0.0 \%)$ & $0(0.0 \%)$ & $0(0.0 \%)$ & $0(0.0 \%)$ & $0(0.0 \%)$ \\
\hline Hypercholesterolemia & $1(2.6 \%)$ & $0(0.0 \%)$ & $0(0.0 \%)$ & $0(0.0 \%)$ & $1(2.4 \%)$ & $1(2.4 \%)$ & $0(0.0 \%)$ & $0(0.0 \%)$ \\
\hline Hypertriglyceridemia & $1(2.6 \%)$ & $0(0.0 \%)$ & $0(0.0 \%)$ & $0(0.0 \%)$ & $1(2.4 \%)$ & $0(0.0 \%)$ & $0(0.0 \%)$ & $0(0.0 \%)$ \\
\hline \multicolumn{9}{|l|}{ Metabolism disorders } \\
\hline AST/ALT increased & $8(21.1 \%)$ & $3(7.9 \%)$ & $2(5.3 \%)$ & $0(0.0 \%)$ & $7(17.1 \%)$ & $1(2.4 \%)$ & $0(0.0 \%)$ & $0(0.0 \%)$ \\
\hline \multicolumn{9}{|l|}{ Musculoskeletal disorders } \\
\hline Arthralgia & $3(7.9 \%)$ & $0(0.0 \%)$ & $0(0.0 \%)$ & $0(0.0 \%)$ & $6(14.6 \%)$ & $2(4.9 \%)$ & $0(0.0 \%)$ & $0(0.0 \%)$ \\
\hline Myalgia & $8(21.1 \%)$ & $0(0.0 \%)$ & $0(0.0 \%)$ & $0(0.0 \%)$ & $7(17.1 \%)$ & $2(4.9 \%)$ & $0(0.0 \%)$ & $0(0.0 \%)$ \\
\hline Septic arthritis & $0(0.0 \%)$ & $0(0.0 \%)$ & $1(2.6 \%)$ & $0(0.0 \%)$ & $0(0.0 \%)$ & $0(0.0 \%)$ & $0(0.0 \%)$ & $0(0.0 \%)$ \\
\hline
\end{tabular}


Nervous system disorders

\begin{tabular}{ccccccccc} 
Sensory Neuropathy & $10(26.3 \%)$ & $1(2.6 \%)$ & $0(0.0 \%)$ & $0(0.0 \%)$ & $19(46.3 \%)$ & $5(12.2 \%)$ & $0(0.0 \%)$ & $0(0.0 \%)$ \\
Dizziness & $1(2.6 \%)$ & $1(2.6 \%)$ & $0(0.0 \%)$ & $0(0.0 \%)$ & $1(2.4 \%)$ & $1(2.4 \%)$ & $0(0.0 \%)$ & $0(0.0 \%)$ \\
Dysgeusia & $1(2.6 \%)$ & $0(0.0 \%)$ & $0(0.0 \%)$ & $0(0.0 \%)$ & $4(9.8 \%)$ & $0(0.0 \%)$ & $0(0.0 \%)$ & $0(0.0 \%)$ \\
$\begin{array}{c}\text { Respiratory disorders } \\
\text { Epistaxis }\end{array}$ & $3(7.9 \%)$ & $0(0.0 \%)$ & $0(0.0 \%)$ & $0(0.0 \%)$ & $9(22.0 \%)$ & $0(0.0 \%)$ & $0(0.0 \%)$ & $0(0.0 \%)$ \\
$\begin{array}{l}\text { Dyspnea } \\
\text { Reproductive system }\end{array}$ & $1(2.6 \%)$ & $0(0.0 \%)$ & $0(0.0 \%)$ & $0(0.0 \%)$ & $3(7.3 \%)$ & $0(0.0 \%)$ & $0(0.0 \%)$ & $0(0.0 \%)$ \\
$\begin{array}{c}\text { Amenorrhea } \\
\text { Cardiac disorders }\end{array}$ & $1(2.6 \%)$ & $3(7.9 \%)$ & $1(2.6 \%)$ & $0(0.0 \%)$ & $0(0.0 \%)$ & $1(2.4 \%)$ & $0(0.0 \%)$ & $0(0.0 \%)$ \\
$\begin{array}{l}\text { Left ventricular } \\
\text { systolic dysfunction }\end{array}$ & $0(0.0 \%)$ & $1(2.6 \%)$ & $0(0.0 \%)$ & $0(0.0 \%)$ & $0(0.0 \%)$ & $1(2.4 \%)$ & $1(2.4 \%)$ & $0(0.0 \%)$ \\
Dilated aortic root & $1(2.6 \%)$ & $0(0.0 \%)$ & $0(0.0 \%)$ & $0(0.0 \%)$ & $0(0.0 \%)$ & $0(0.0 \%)$ & $0(0.0 \%)$ & $0(0.0 \%)$ \\
\hline
\end{tabular}

Data are $N(\%)$.

outcomes on early BC in 3,649 women [10], will be of great interest to confirm or reject [72] the causal nature of the suggested correlation between metformin use and survival benefit in $\mathrm{BC}$ patients.

\section{MATERIALS AND METHODS}

\section{Study design and objectives}

Patients were randomly assigned to receive daily metformin (850 mg twice-daily) for 24 weeks concurrently with 12 cycles of weekly paclitaxel plus trastuzumab followed by four cycles of 3-weekly fluorouracil, epirubicin, cyclophosphamide plus trastuzumab (arm A) or equivalent sequential chemotherapy plus trastuzumab without metformin (arm B), followed by surgery.

The primary end point was pCR, defined as absence of invasive tumor cells on hematoxylin and eosin evaluation of the complete resected breast specimen (and all sample regional lymph nodes if lymphadenectomy was performed) following the completion of neoadjuvant systemic therapy. Residual ductal carcinoma in situ (DCIS) only was included in the definition of pCR (ypT0/is, ypN0). Secondary aims included the tolerability and safety profile of the metformin-based neoadjuvant combination including cardiac toxicity, the rate of breast conservation,

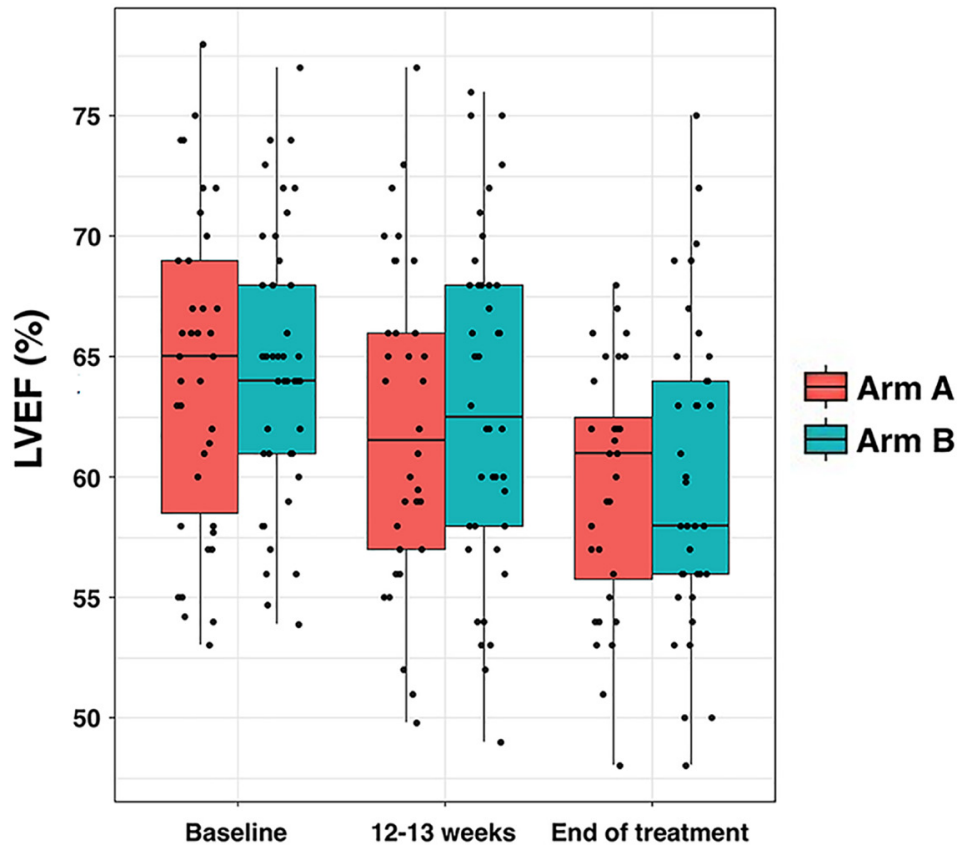

Figure 4: Left ventricular ejection fraction (LVEF) per treatment arm. Box plots indicating median (black lines within the boxes), interquartile ranges, whiskers and ranges for LVEF at baseline, after 12-13 weeks, and at the end of therapy. 
Table 5: Left ventricular ejection fraction (LVEF) in the mITT population

\begin{tabular}{|c|c|c|c|}
\hline & $\operatorname{Arm} \mathbf{A}$ & Arm B & \\
\hline At baseline & $N=38$ & $N=41$ & \\
\hline Median (IQR) & $65.0 \%(58.0$ to 69.3$)$ & $64.0 \%(61.0$ to 68.5$)$ & \\
\hline Week 12 & $N=34$ & $N=40$ & \\
\hline Median change from baseline (IQR) & $-1.5 \%(-6.6$ to 1.2$)$ & $-1.0 \%(-6.8$ to 4.0$)$ & \\
\hline LVEF measurement $(N, \%)$ & & & $P=0.032$ \\
\hline No decrease or decrease $<10 \%$, still above LLN & $32(94.1 \%)$ & $33(82.5 \%)$ & \\
\hline Decrease $<10 \%$, below LLN & $1(2.9 \%)$ & $1(2.5 \%)$ & \\
\hline Decrease $10-15 \%$, still above LLN & $0(0.0 \%)$ & $6(15.0 \%)$ & \\
\hline Decrease $10-15 \%$, below LLN & $0(0.0 \%)$ & $0(0.0 \%)$ & \\
\hline Decrease $>15 \%$, still above LLN & $1(2.9 \%)$ & $0(0.0 \%)$ & \\
\hline Decrease $>15 \%$, below LLN & $0(0.0 \%)$ & $0(0.0 \%)$ & \\
\hline End of treatment & $N=32$ & $N=37$ & \\
\hline Median change from baseline (IQR) & $-4.0 \%(-6.0$ to -1.8$)$ & $-5.0 \%(-7.5$ to -1.0$)$ & \\
\hline \multicolumn{4}{|l|}{ LVEF measurement $(N, \%)$} \\
\hline No decrease or decrease $<10 \%$, still above LLN & $27(84.4 \%)$ & $30(81.1 \%)$ & $P=0.409$ \\
\hline Decrease $<10 \%$, below LLN & $1(3.1 \%)$ & $0(0.0 \%)$ & \\
\hline Decrease $10-15 \%$, still above LLN & $2(6.3 \%)$ & $3(8.1 \%)$ & \\
\hline Decrease $10-15 \%$, below LLN & $0(0.0 \%)$ & $3(8.1 \%)$ & \\
\hline Decrease $>15 \%$, still above LLN & $2(6.3 \%)$ & $1(2.7 \%)$ & \\
\hline Decrease $>15 \%$, below LLN & $0(0.0 \%)$ & $0(0.0 \%)$ & \\
\hline
\end{tabular}

Data are median (IQR) or $N(\%)$ unless stated otherwise.

LLN, lower limit of institutional normal; LVEF, left ventricular ejection fraction.

5-year disease-free survival (DFS), the inhibition of tumor tissue biomarkers (including proliferative, mTOR/AMPKand HER2-related pathways), and changes in circulating levels of insulin and metabolites. Studies of disease free survival rates and correlative biological markers are ongoing and will be reported separately. Independent institutional review boards approved the study protocol and any amendments. Written informed consent was obtained from each participant. The study was registered with the EU Clinical Trials Register and is available online (https://www.clinicaltrialsregister.eu/ctr-search/ trial/2011-000490-30/ES).

\section{Patient selection}

Patients were eligible if they met the following criteria: previously untreated, operable, locally advanced, or inflammatory $\mathrm{BC}>2.0 \mathrm{~cm}$ in largest clinical diameter, and confirmed HER 2 positivity (either immunohistochemistry $3+$ or $2+$ and positive for fluorescent or chromogenic in situ hybridization). Patients were excluded from this study if they had impaired cardiac function (e.g., uncontrolled or symptomatic angina, clinically significant arrhythmias, congestive heart failure, transmural myocardial infarction), uncontrolled hypertension, concurrent treatment with therapies that can alter insulin levels (including chronic treatment with oral corticoids), metabolic disease (e.g., diabetes mellitus type I or II, obesity [BMI $>30$ ], impaired glucose tolerance [ $>128 \mathrm{mg} / \mathrm{dL}]$, hypercholesterolemia or hypertriglyceridemia of grade $\geq 3$ according to CTC-NCIC version 4.0). See Supplementary Materials for additional inclusion and exclusion criteria.

\section{Treatment}

Chemotherapy consisted of weekly paclitaxel $\left(80 \mathrm{mg} / \mathrm{m}^{2}\right)$ for 12 weeks, concomitant trastuzumab $(4 \mathrm{mg} / \mathrm{kg}$ loading dose followed by $2 \mathrm{mg} / \mathrm{kg}$ weekly for 12 weeks), followed by four courses of fluorouracil $\left(600 \mathrm{mg} / \mathrm{m}^{2}\right)$, epirubicin $\left(75 \mathrm{mg} / \mathrm{m}^{2}\right)$, and cyclophosphamide $\left(600 \mathrm{mg} / \mathrm{m}^{2}\right)$ $\left(\mathrm{FE}_{75} \mathrm{C}\right)$, administered every 3 weeks with concomitant trastuzumab $(6 \mathrm{mg} / \mathrm{kg})$. Corticosteroids and histaminereceptor blockers were administered before paclitaxel. Patients on arm A received concomitant metformin ( $850 \mathrm{mg}$ twice-daily) for 24 weeks, which was given in divided doses with meals, with gradual dose escalation to reduce gastrointestinal side effects. The starting dose was $425 \mathrm{mg}$ (one-half of a tablet) daily with dinner; dosage 
increase was carried out in increments of $425 \mathrm{mg}$ every week to a total of $850 \mathrm{mg}$ twice-daily after 4 weeks. Patients had surgery within 4-5 weeks of the last cycle of neoadjuvant treatment. Post-surgery, patients received 3-weekly trastuzumab to complete 1 year of neoadjuvantadjuvant therapy. Radiotherapy and endocrine therapy were according to local guidelines.

\section{Randomization and masking}

Patients were randomly assigned (1:1 ratio) to arm A or arm B with a dynamic randomized block design and a minimization technique. Stratification factors were: age ( $<50$ years vs $\geq 50$ years); clinical tumor size (T2 $[2-5 \mathrm{~cm}$ diameter] vs $\geq \mathrm{T} 3$ [ $>5 \mathrm{~cm}$ diameter]); clinical involvement of axillary lymph nodes (N0-1 vs $\geq 2$ ); and hormone receptor (HR) status (estrogen receptor or progesteronereceptor $[\mathrm{PgR}]$ positive; or both, vs estrogen-receptor and PgR negative). Two hundred and fifty-six randomization codes were generated with a block size of 16 patients $(8$ per arm) per combined strata. On verification of patients' eligibility, investigators were immediately notified of the allocated treatment.

\section{Assessments}

Grading of all adverse events (AEs) was made using National Cancer Institute Common Terminology Criteria for Adverse Events (NCI CTCAE) version 4.0, and reported as cumulative incidence. Cardiac safety was monitored via incidence of significant asymptomatic left ventricular systolic dysfunction (LVSD), which was defined as $\geq 10 \%$ decline in left ventricular ejection fraction (LVEF) from baseline to $<50 \%$ over the course of neoadjuvant treatment. LVEF was evaluated before study, after 12 weeks, and at the completion of treatment. Symptomatic LVSD was reported as a serious AE. Ink marks or surgical clips were used to mark the tumor bed before beginning neoadjuvant therapy, to facilitate surgical procedures and pathology. The Oracle Clinical ${ }^{\circledR}$ software tool was employed to assist with data management, data entry, and data validation.

\section{Analytical determination of circulating metformin in serum}

Serum was collected at the end of the 24-week intervention and stored at $-80^{\circ} \mathrm{C}$ until assayed. Metformin concentrations were determined using high-performance liquid chromatography coupled to electrospray ionization and quadrupole time-of-flight mass spectrometry (HPLC-ESI-QTOF-MS). See Supplementary Materials for a detailed description of the analytical method.

\section{Sample size and statistical analysis}

A Jung's two-stage design for randomized phase II trials with a prospective control [73] was used to estimate the sample size. To keep the sample size small and the study period short, we employed a relatively large type I error $(\alpha=15 \%)$ and a short-term outcome variable, the percentage of $\mathrm{pCR}$ as primary endpoint, which allowed for early termination of the study if the metformin containing arm failed to show efficacy at the interim analysis. The combination metformin plus chemotherapy/trastuzumab was considered worthwhile if a $\mathrm{pCR} \geq 75 \%$ was obtained. By setting an $\alpha$ level of 0.15 , a power of 0.80 , a balanced allocation (1:1), and an expected drop-out rate of $25 \%$, the sample size was 47 patients for arms A and B to ensure a perprotocol (PP) assessment of pCR in 37 patients in each arm at the first stage. Only if at least two more patients achieved a pCR in the metformin-containing arm than in the reference arm, and provided no safety issues were identified, would the clinical trial proceed to the second stage. In such case, an additional recruitment of 65 patients for arms $A$ and $B$ (to ensure a PP assessment of pCR in 52 patients in each arm), will proceed. The metformin-containing arm was considered effective if 5 or more additional patients achieved a pCR in comparison with the reference arm at the end of the study ( $N=224$ patients at the planned final sample size).

The modified intention-to-treat (mITT)/safety population included all randomly assigned patients who received at least one dose of study medication. The PP/ efficacy population included all participants in the mITT population who had not violated any inclusion or exclusion criteria or deviated from the protocol in a way that could affect their efficacy assessments including sufficient treatment duration.

Safety and efficacy parameters were evaluated descriptively. Categorical parameters are presented as frequencies $(N, \%)$ and were compared using a chisquared test (or Fisher's exact test, when appropriate). Continuous variables are presented as mean \pm standard deviation or median (1st/3rd quartile) and were compared using Student's unpaired $t$-test or the Mann-Whitney $U$ test when data were not normally distributed. Data normality before statistical analyses was assessed with the Kolmogorov-Smirnov test. Binary logistic regression was used to assess the prognostic effect of baseline characteristics on pCR. Unadjusted and adjusted odds ratios (ORs) with their relative $95 \%$ confidence intervals (CIs) were reported as a measure of association. After 84 of 224 planned patients were randomized, the trial was closed early due to slow recruitment, which left the study underpowered relative to its primary endpoint (i.e., pCR). Therefore, the analyses presented here are considered exploratory and $P$ values should not be used for drawing conclusions about the impact on pCR when adding neoadjuvant metformin to trastuzumab and chemotherapy.

Statistical analyses were carried out using SPSS (IBM Corp. released 2016. IBM SPSS Statistics for Windows, Version 24.0; Armonk, NY) and STATA (StataCorp. 2013. Stata Statistical Software: Release 13; StataCorp LP, College Station, TX). 


\section{CONCLUSIONS}

Larger studies are needed to determine if the similar high percentages of pCR observed in both treatment arms in the METTEN study reflects true lack of clinical efficacy of metformin or whether the study was underpowered for drawing conclusions about metformin effectiveness. Nevertheless, the METTEN study provides useful information, revealing that the addition of a conventional anti-diabetic dose of metformin to complex neoadjuvant regimens involving anthracycline/taxane-based chemotherapy and targeted therapies such as trastuzumab is well tolerated and safe.

\section{Abbreviations}

METTEN: Metformin and Trastuzumab in Neoadjuvancy (METformina y Trastuzumab En Neoadyuvancia, Spanish); BC: Breast Cancer; pCR: pathological Complete Response; AEs: Adverse effects; FE75C: Fluorouracil, Epirubicin $\left(75 \mathrm{mg} / \mathrm{m}^{2}\right)$, and Cyclophosphamide; T2D: Type 2 diabetes; HR: Hormone Receptor; ER: Estrogen Receptor; PgR: Progesterone receptor; LEVF: Left Ventricular Ejection Fraction; PP: Per-Protocol; ITT: Intention-to-treat; HPLC-ESI-QTOFMS: High-performance liquid chromatography coupled to electrospray ionization and quadrupole time-of-flight mass spectrometry; OXPHOS: Oxidative Phosphorylation; ORs: Odds Ratios.

\section{Author contributions}

Conception and design: B Martin-Castillo, JA Menendez; Study coordination: B Martin-Castillo; Acquisition of data (e.g., acquired and managed patients, performed analytical determinations): S. Pernas, J. Dorca, I. Álvarez, S. Martínez, JM Pérez-Garcia, N. Batista-López, CA Rodríguez-Sánchez, K. Amillano, S. Domínguez, M. Luque, A. Stradella, I. Morilla, G. Viñas, J. Cortés, E. Cuyàs, S. Verdura, Á. Fernández-Ochoa, S. FernándezArroyo, A. Segura-Carretero, J. Joven, E. Pérez, E. LópezBonet; Analysis and data interpretation (e.g., development of methodology, statistical analysis, biostatistics): M Buxó, B Martin-Castillo, JA Menendez; Administrative and technical support (e.g., reporting or organizing data, constructing databases): N. Bosch, M. Garcia, M Buxó, S. Saidani. Writing, review, and/or revision of the manuscript: JA Menendez, B Martin-Castillo. All authors read and approved the final manuscript for submission.

\section{ACKNOWLEDGMENTS}

The METTEN study was conceived and designed by Begoña Martin-Castillo and Javier A. Menendez. The METTEN study was sponsored by the Consortium for the Support of Biomedical Research Network (CAIBER) and the Catalan Institute of Oncology (ICO). The funding sources and sponsors did not have a role in either data analysis or in writing of the report. The Unit of Clinical Research at the ICO in Girona and the Unit for Statistical and Methodological Assessment at the Girona Biomedical Research Institute (IDIBGI) were responsible for central data gathering and analysis. All authors had responsibility for the decision to submit for publication. Work in the Javier A. Menendez laboratory is supported by the Ministerio de Ciencia e Innovación (Grant SAF2016-80639-P), Plan Nacional de 1+D+I, Spain. The authors would like to thank Dr. Kenneth McCreath for editorial support.

\section{Ethics statement}

The hospital (Dr. Josep Trueta Hospital, Girona, Spain) ethics committee (Clinical Investigation Ethic Committee, CIEC) and independent institutional review boards at each site participating in the METTEN study approved the protocol and any amendments. All procedures were in accordance with the ethical standards of the institutional research committees and with the 1964 Helsinki declaration and its later amendments or comparable ethical standards. Informed consent was obtained from all individual participants included in the study.

\section{Availability of data and material}

The study was registered with the EU Clinical Trials Register and is available online (https://www. clinicaltrialsregister.eu/ctr-search/trial/2011-000490-30/ES).

\section{CONFLICTS OF INTEREST}

The authors declared that they have no competing interests.

\section{FUNDING}

This work was supported by grants from the Ministerio de Sanidad, Servicios Sociales e Igualdad (EC10-125, Ayudas para el Fomento de la Investigación Clínica Independiente to Begoña Martin-Castillo).

\section{REFERENCES}

1. Decensi A, Puntoni M, Goodwin P, Cazzaniga M, Gennari A, Bonanni B, Gandini S. Metformin and cancer risk in diabetic patients: a systematic review and meta-analysis. Cancer Prev Res (Phila). 2010; 3:1451-1461.

2. Col NF, Ochs L, Springmann V, Aragaki AK, Chlebowski RT. Metformin and breast cancer risk: a meta-analysis and critical literature review. Breast Cancer Res Treat. 2012; 135:639-646.

3. Gandini S, Puntoni M, Heckman-Stoddard BM, Dunn BK, Ford L, DeCensi A, Szabo E. Metformin and cancer 
risk and mortality: a systematic review and meta-analysis taking into account biases and confounders. Cancer Prev Res (Phila). 2014; 7:867-885.

4. Del Barco S, Vazquez-Martin A, Cutí S, Oliveras-Ferraros C, Bosch-Barrera J, Joven J, Martin-Castillo B, Menendez JA. Metformin: multi-faceted protection against cancer. Oncotarget. 2011; 2:896-917. https://doi.org/10.18632/ oncotarget.387.

5. Pollak M. Potential applications for biguanides in oncology. J Clin Invest. 2013; 123:3693-3700.

6. Foretz M, Guigas B, Bertrand L, Pollak M, Viollet B. Metformin: from mechanisms of action to therapies. Cell Metab. 2014; 20:953-966.

7. Bodmer M, Meier C, Krahenbühl S, Jick SS, Meier CR. Metformin, sulfonylureas, or other antidiabetes drugs and the risk of lactic acidosis or hypoglycemia: a nested casecontrol analysis. Diabetes Care. 2008; 31:2086-2091.

8. Salpeter SR, Greyber E, Pasternak GA, Salpeter EE. Risk of fatal and nonfatal lactic acidosis with metformin use in type 2 diabetes mellitus. Cochrane Database Syst Rev. 2010; 4:CD002967.

9. Goodwin PJ, Stambolic V, Lemieux J, Chen BE, Parulekar WR, Gelmon KA, Hershman DL, Hobday TJ, Ligibel JA, Mayer IA, Pritchard KI, Whelan TJ, Rastogi P, et al. Evaluation of metformin in early breast cancer: a modification of the traditional paradigm far clinical testing of anti-cancer agents. Breast Cancer Res Treat. 2011; 126:215-220.

10. Goodwin PJ, Parulekar WR, Gelmon KA, Shepherd LE, Ligibel JA, Hershman DL, Rastogi P, Mayer IA, Hobday TJ, Lemieux J, Thompson AM, Pritchard KI, Whelan TJ, et al. Effect of metformin vs placebo on and metabolic factors in NCIC CTG MA.32. J Natl Cancer Inst. 2015; 107:djv006.

11. Pollak MN. lnvestigating metformin for cancer prevention and treatment: the end of the beginning. Cancer Discov. 2012; 2:778-790.

12. Esserman LJ, Berry DA, DeMichele A, Carey L, Davis SE, Buxton M, Hudis C, Gray JW, Perou C, Yau C, Livasy C, Krontiras H, Montgomery L, et al. Pathologic complete response predicts recurrence-free survival more effectively by cancer subset: results from the I-SPY 1 TRIALCALGB 150007/150012, ACRIN 6657. J Clin Oncol. 2012; 30:3242-3249.

13. Cortazar P, Zhang L, Untch M, Mehta K, Costantino JP, Wolmark N, Bonnefoi H, Cameron D, Gianni L, Valagussa P, Swain SM, Prowell T, Loibl S, et al. Pathological complete response and long-term clinical benefit in breast cancer: the CTNeoBC pooled analysis. Lancet. 2014; 384:164-172.

14. Berry DA, Hudis CA. Neoadjuvant Therapy in Breast Cancer as a Basis for Drug Approval. JAMA Oncol. 2015; 1:875-876.

15. DeMichele A, Yee D, Berry DA, Albain KS, Benz CC, Boughey J, Buxton M, Chia SK, Chien AJ, Chui SY, Clark
A, Edmiston K, Elias AD, et al. The Neoadjuvant Model Is Still the Future for Drug Development in Breast Cancer. Clin Cancer Res. 2015; 21:2911-2915.

16. Jiralerspong S, Palla SL, Giordano SH, Meric-Bernstam F, Liedtke C, Barnett CM, Hsu L, Hung MC, Hortobagyi GN, Gonzalez-Angulo AM. Metformin and pathologic complete responses to neoadjuvant chemotherapy in diabetic patients with breast cancer. J Clin Oncol. 2009; 27:3297-3302.

17. Kim J, Lee J, Kim C, Choi J, Kim A. Anti-cancer effect of metformin by suppressing signaling pathway of HER 2 and HER3 in tamoxifen-resistant breast cancer cells. Tumour Biol. 2016; 37:5811-5819.

18. Vazquez-Martin A, Oliveras-Ferraros C, Menendez JA. The antidiabetic drug metformin suppresses HER2 (erbB2) oncoprotein overexpression via inhibition of the mTOR effector p70S6K1 in human breast carcinoma cells. Cell Cycle. 2009; 8:88-96.

19. Vázquez-Martín A, Oliveras-Ferraros C, del Barco S, Martín-Castillo B, Menéndez JA. mTOR inhibitors and the anti-diabetic biguanide metformin: new insights into the molecular management of breast cancer resistance to the HER2 tyrosine kinase inhibitor lapatinib (Tykerb). Clin Transl Oncol. 2009; 11:455-459.

20. Vazquez-Martin A, Oliveras-Ferraros C, del Barco S, Martin-Castillo B, Menéndez JA. The antidiabetic drug metformin: a pharmaceutical AMPK activator to overcome breast cancer resistance to HER2 inhibitors while decreasing risk of cardiomyopathy. Ann Oncol. 2009; 20:592-595.

21. Anisimov VN, Egarmin PA, Piskunova TS, Popovich IG, Tyndyk ML, Yurova MN, Zabezhinski MA, Anikin IV, Karkach AS, Romanyukha AA. Metformin extends lite span of HER-2/neu transgenic mice and in combination with melatonin inhibits growth of transplantable tumors in vivo. Cell Cycle. 2010; 9:188-197.

22. Ben Sahra I, Le Marchand-Brustel Y, Tanti JF, Bost F. Metformin in cancer therapy: a new perspective for an old antidiabetic drug? Mol Cancer Ther. 2010; 9:1092-1099.

23. Goodwin PJ, Pritchard KI, Ennis M, Clemons M, Graham M, Fantus IG. Insulinlowering effects of metformin in women with early breast cancer. Clin Breast Cancer. 2008; 8:501-505.

24. Jalving M, Gietema JA, Lefrandt JD, de Jong S, Reyners AK, Gans RO, de Vries EG. Metformin: taking away the candy for cancer? Eur J Cancer. 2010; 46:2369-2380.

25. Pollak M. Insulin and insulin-like growth factor signalling in neoplasia. Nat Rev Cancer. 2008; 8:915-928.

26. Feng YH, Velazquez-Torres G, Gully C, Chen J, Lee MH, Yeung SC. The impact of type 2 diabetes and antidiabetic drugs on cancer cell growth. J Cell Mol Med. 2011; 15:825-836.

27. He L, Wondisford FE. Metformin action: concentrations matter. Cell Metab. 2015; 21:159-162.

28. Nahta R, O'Regan RM. Evolving strategies for overcoming resistance to HER2- directed therapy: targeting the $\mathrm{Pl3K} /$ Akt/mTOR pathway. Clin Breast Cancer. 2010; 10:S72-S78. 
29. Vazquez-Martin A, Oliveras-Ferraros C, Del Barco S, Martin-Castillo B, Menendez JA. The anti-diabetic drug metformin suppresses self-renewal and proliferation of trastuzumab-resistant tumor-initiating breast cancer stem cells. Breast Cancer Res Treat. 2011; 126:355-364.

30. Zhu P, Davis M, Blackwelder AJ, Bachman N, Liu B, Edgerton S, Williams LL, Thor AD, Yang X. Metformin selectively targets tumor-initiating cells in ErbB2overexpressing breast cancer models. Cancer Prev Res (Phila). 2014; 7:199-210.

31. Tucker GT, Casey C, Phillips PJ, Connor H, Ward JD, Woods HF. Metformin kinetics in healthy subjects and in patients with diabetes mellitus. Br J Clin Pharmacol. 1981; 12:235-246.

32. Christensen MM, Brasch-Andersen C, Green $H$, Nielsen F, Damkier P, Beck-Nielsen H, Brosen K. The pharmacogenetics of metformin and its impact on plasma metformin steady-state levels and glycosylated hemoglobin A1c. Pharmacogenet Genomics. 2011; 21:837-850.

33. Martin-Castillo B, Dorca J, Vazquez-Martin A, OliverasFerraros C, Lopez-Bonet E, Garcia M, Del Barco S, Menendez JA. Incorporating the antidiabetic drug metformin in HER2-positive breast cancer treated with neo-adjuvant chemotherapy and trastuzumab: an ongoing clinical-translational research experience at the Catalan Institute of Oncology. Ann Oncol. 2010; 21:187-189.

34. Buzdar AU, lbrahim NK, Francis D, Booser DJ, Thomas ES, Theriault RL, Pusztai L, Green MC, Arun BK, Giordano SH, Cristofanilli M, Frye DK, Smith TL, et al. Significantly higher pathologic complete remission rate after neoadjuvant therapy with trastuzumab, paclitaxel, and epirubicin chemotherapy: results of a randomized trial in human epidermal growth factor receptor 2- positive operable breast cancer. J Clin Oncol. 2005; 23:3676-3685.

35. Buzdar AU, Suman VJ, Meric-Bernstam F, Leitch AM, Ellis MJ, Boughey JC, Unzeitig G, Royce M, McCall LM, Ewer MS, Hunt KK; American College of Surgeons Oncology Group investigators. Fluorouracil, epirubicin, and cyclophosphamide (FEC-75) followed by paclitaxel plus trastuzumab versus paclitaxel plus trastuzumab followed by FEC-75 plus trastuzumab as neoadjuvant treatment for patients with HER2-positive breast cancer (Z1041): a randomised, controlled, phase 3 trial. Lancet Oncol. 2013; 14:1317-1325.

36. Pernas S, Gil-Gil M, de Olza MO, Gumà A, Climent F, Petit A, Pla MJ, García-Tejedor A, López-Ojeda A, Falo C, Fernandez-Otega A, Mesia C, Pérez-Martin FJ, et al. Efficacy and safety of concurrent trastuzumab plus weekly paclitaxel-FEC as primary therapy for HER2-positive breast cancer in everyday clinical practice. Breast Cancer Res Treat. 2012; 134:1161-1168.

37. Gianni L, Eiermann W, Semiglazov V, Manikhas A, Lluch A, Tjulandin S, Zambetti M, Vazquez F, Byakhow M, Lichinitser M, Climent MA, Ciruelos E, Ojeda B, et al. Neoadjuvant chemotherapy with trastuzumab followed by adjuvant trastuzumab versus neoadjuvant chemotherapy alone, in patients with HER2-positive locally advanced breast cancer (the NOAH trial): a randomised controlled superiority trial with a parallel HER2-negative cohort. Lancet. 2010; 375:377-384.

38. Untch M, Loibl S, Bischoff J, Eidtmann H, Kaufmann M, Blohmer JU, Hilfrich J, Strumberg D, Fasching PA, Kreienberg R, Tesch H, Hanusch C, Gerber B, et al. Lapatinib versus trastuzumab in combination with neoadjuvant anthracycline-taxane-based chemotherapy (GeparQuinto, GBG 44): a randomised phase 3 trial. Lancet Oncol. 2012; 13:135-144.

39. Ismael G, Hegg R, Muehlbauer S, Heinzmann D, Lum B, Kim SB, Pienkowski T, Lichinitser M, Semiglazov V, Melichar B, Jackisch C. Subcutaneous versus intravenous administration of (neo)adjuvant trastuzumab in patients with HER2- positive, clinical stage 1-111 breast cancer (HannaH study): a phase 3, open label, multicentre, randomised trial. Lancet Oncol. 2012; 13:869-878.

40. Rastogi P, Anderson SJ, Bear HD, Geyer CE, Kahlenberg MS, Robidoux A, Margolese RG, Hoehn JL, Vogel VG, Dakhil SR, Tamkus D, King KM, Pajon ER, et al. Preoperative chemotherapy: updates of National Surgical Adjuvant Breast and Bowel Project Protocols B-18 and B-27. J Clin Oncol. 2008; 26:778-785.

41. He X, Esteva FJ, Ensor J, Hortobagyi GN, Lee MH, Yeung SC. Metformin and thiazolidinediones are associated with improved breast cancer-specific survival of diabetic women with HER2+ breast cancer. Ann Oncol. 2012; 23:1771-1780.

42. Guiu S, Mouret Reynier MA, Toure M, Coudert B. Predictive Factors of Response in HER2-Positive Breast Cancer Treated by Neoadjuvant Therapy. J Oncol. 2013; 2013:854121.

43. Pernas Simon S. Neoadjuvant therapy of early stage human epidermal growth factor receptor 2 positive breast cancer: latest evidence and clinical implications. Ther Adv Med Oncol. 2014; 6:210-221.

44. Zhang B, Hurvitz S. Long-term outcomes of neoadjuvant treatment of HER2- positive breast cancer. Clin Adv Hematol Oncol. 2016; 14:520-530.

45. Guarneri V, Frassoldati A, Bottini A, Cagossi K, Bisagni G, Sarti S, Ravaioli A, Cavanna L, Giardina G, Musolino A; Untch M, Orlando L, Artioli F, Boni C, et al. Preoperative chemotherapy plus trastuzumab, lapatinib, or both in human epidermal growth factor receptor 2-positive operable breast cancer: results of the randomized phase 11 CHER-LOB study. J Clin Oncol. 2012; 30:1989-1995.

46. Kim HJ, Kwon H, Lee JW, Kim HJ, Lee SB, Park HS, Sohn G, Lee Y, Koh BS, Yu JH, Son BH, Ahn SH. Metformin increases survival in hormone receptor-positive, HER2positive breast cancer patients with diabetes. Breast Cancer Res. 2015; 17:64.

47. Sonnenblick A, Agbor-Tarh D, Bradbury I, Di Cosimo S, Azim HA Jr, Fumagalli D, Sarp S, Wolff AC, Andersson M, Kroep J, Cufer T, Simon SD, Salman P, et al. Impact of 
Diabetes, lnsulin, and Metformin Use on the Outcome of Patients With Human Epidermal Growth Factor Receptor 2-Positive Primary Breast Cancer: Analysis From the ALTTO Phase 111 Randomized Trial. J Clin Oncol. 2017; 35:1421-1429.

48. von Minckwitz G, Untch M, Blohmer JU, Costa SD, Eidtmann H, Fasching PA, Gerber B, Eiermann W, Hilfrich J, Huober J, Jackisch C, Kaufmann M, Konecny GE, et al. Definition and impact of pathologic complete response on prognosis after neoadjuvant chemotherapy in various intrinsic breast cancer subtypes. J Clin Oncol. 2012; 30:1796-1804.

49. Gianni L, Pienkowski T, $\operatorname{lm}$ YH, Roman L, Tseng LM, Liu MC, Lluch A, Staroslawska E, de la Haba-Rodríguez J, $1 \mathrm{~m}$ SA, Pedrini JL, Poirier B, Morandi P, et al. Efficacy and safety of neoadjuvant pertuzumab and trastuzumab in women with locally advanced, inflammatory, or early HER2- positive breast cancer (NeoSphere): a randomised multicentre, open-label, phase 2 trial. Lancet Oncol. 2012; 13:25-32.

50. Wuerstlein R, Harbeck N. Neoadjuvant therapy for HER2positive breast cancer. Rev Recent Clin Trials. 2017; 12:81-92.

51. Robert F, Fendri S, Hary L, Lacroix C, Andréjak M, Lalau JD. Kinetics of plasma and erythrocyte metformin after acute administration in healthy subjects. Diabetes Metab. 2003; 29:279-283.

52. Chae YK, Arya A, Malecek MK, Shin DS, Carneiro B, Chandra S, Kaplan J, Kalyan A, Altman JK, Platanias L, Giles F. Repurposing metformin for cancer treatment: current clinical studies. Oncotarget. 2016; 7:40767-40780. https://doi.org/10.18632/oncotarget.8194.

53. MacKenzie MJ, Ernst S, Johnson C, Winquist E. A phase I study of temsirolimus and metformin in advanced solid tumours. Invest New Drugs. 2012; 30:647-652.

54. Kritharis A, Caplain J, Rajagopal S, Grimm E, Tsichlis PN, Martell R, Saif WM. A phase I study of metformin and chemotherapy in salid tumors. J Clin Oncol. 2014; 32:5.

55. Penault-Llorca F, Radosevic-Robin N. Biomarkers of residual disease after neoadjuvant therapy for breast cancer. Nat Rev Clin Oncol. 2016; 13:487-503.

56. Havas KM, Milchevskaya V, Radic K, Alladin A, Kafkia E, Garcia M, Stolte J, Klaus B, Rotmensz N, Gibson TJ, Burwinkel B, Schneeweiss A, Pruneri G, et al. Metabolic shifts in residual breast cancer drive tumor recurrence. J Clin Invest. 2017; 127:2091-2105.

57. Seidman A, Hudis C, Pierri MK, Shak S, Paton V, Ashby M, Murphy M, Stewart SJ, Keefe D. Cardiac dysfunction in the trastuzumab clinical trials experience. J Clin Oncol. 2002; 20:1215-1221.

58. Force T, Krause DS, Van Etten RA. Molecular mechanisms of cardiotoxicity of tyrosine kinase inhibition. Nat Rev Cancer. 2007; 7:332-344.

59. Spector NL, Yarden Y, Smith B, Lyass L, Trusk P, Pry K, Hill JE, Xia W, Seger R, Bacus SS. Activation of
AMP-activated protein kinase by human EGF receptor 2/ EGF receptor tyrosine kinase inhibitor protects cardiac cells. Proc Natl Acad Sci U S A. 2007; 104:10607-10612.

60. Shell SA, Lyass L, Trusk PB, Pry KJ, Wappel RL, Bacus SS. Activation of AMPK is necessary for killing cancer cells and sparing cardiac cells. Cell Cycle. 2008; 7:1769-1775.

61. Zhang L, He H, Balschi JA. Metformin and phenformin activate AMP-activated protein kinase in the heart by increasing cytosolic AMP concentration. Am J Physiol Heart Circ Physiol. 2007; 293:H457-H466.

62. Necela BM, Axenfeld BC, Serie DJ, Kachergus JM, Perez EA, Thompson EA, Norton N. The antineoplastic drug, trastuzumab, dysregulates metabolites in iPSC-derived cardiomyocytes. Clin Transl Med. 2017; 6:5.

63. Schneeweiss A, Chia S, Hickish T, Harvey V, Eniu A, Hegg R, Tausch C, Seo JH, Tsai YF, Ratnayake J, McNally V, Ross G, Cortés J. Pertuzumab plus trastuzumab in combination with standard neoadjuvant anthracyclinecontaining and anthracycline-free chemotherapy regimens in patients with HER2-positive early breast cancer: a randomized phase II cardiac safety study (TRYPHAENA). Ann Oncol. 2013; 24:2278-2284.

64. Swain SM, Baselga J, Kim SB, Ro J, Semiglazov V, Campone M, Ciruelos E, Ferrero JM, Schneeweiss A, Heeson S, Clark E, Ross G, Benyunes MC, et al. Pertuzumab, trastuzumab, and docetaxel in HER2-positive metastatic breast cancer. N Engl J Med. 2015; 372:724-734.

65. Gyawali B, Pantziarka P, Crispino S, Bouche G. Does the oncology community have a rejection bias when it comes to repurposed drugs? Ecancermedicalscience. 2018; 12:ed76.

66. Kordes S, Pollak MN, Zwinderman AH, Mathôt RA, Weterman MJ, Beeker A, Punt CJ, Richel DJ, Wilmink JW. Metformin in patients with advanced pancreatic cancer: a double-blind, randomised, placebo-controlled phase 2 trial. Lancet Oncol. 2015; 16:839-847.

67. Reni M, Dugnani E, Cereda S, Belli C, Balzano G, Nicoletti R, Liberati D, Pasquale V, Scavini M, Maggiora P, Sordi V, Lampasona V, Ceraulo D, et al. (Ir)relevance of Metformin Treatment in Patients with Metastatic Pancreatic Cancer: An Open-Label, Randomized Phase II Trial. Clin Cancer Res. 2016; 22:1076-1085.

68. Menendez JA, Quirantes-Piné R, Rodríguez-Gallego E, Cufí S, Corominas-Faja B, Cuyàs E, Bosch-Barrera J, Martin-Castillo B, Segura-Carretero A, Joven J. Oncobiguanides: Paracelsus' law and nonconventional routes for administering diabetobiguanides for cancer treatment. Oncotarget. 2014; 5:2344-2348. https://doi. org/10.18632/oncotarget.1965.

69. Menendez JA, Martin-Castillo B, Joven J. Metformin and cancer: Quo vadis et cui bono? Oncotarget. 2016; 7:5409654101. https://doi.org/10.18632/oncotarget.10262.

70. Pollak M. Overcoming Drug Development Bottlenecks With Repurposing: Repurposing biguanides to target energy metabolism for cancer treatment. Nat Med. 2014; 20:591-593. 
71. Berstein LM. Metformin: not only per os. Expert Rev Endocrinol Metab. 2018; 13:63-65.

72. Suissa S. Metformin to Treat Cancer: Misstep in Translational Research from Observational Studies. Epidemiology. 2017; 28:455-458.
73. Jung SH. Randomized phase II trials with a prospective control. Stat Med. 2008; 27:568-583. 